\title{
Comparative Study of the Aromatic Profiles of Two Different Plum Species: Prunus salicina Lindl and Prunus simonii L
}

\author{
Encarna Gómez and Craig A Ledbetter* \\ US Department of Agriculture, Agricultural Research Service, 2021 South Peach Avenue, Fresno, \\ California 93727-5951, USA
}

(Received 16 April 1993; revised version 16 November 1993; accepted 5 January 1994)

\begin{abstract}
Volatile compounds of two plum species (Prunus salicina Lindl and Prunus simonii L) were analyzed by capillary gas chromatography-mass spectrometry using simultaneous vacuum distillation extraction. Aroma patterns were identified and quantified. A total of 60 compounds were identified, of which 23 were unique to $P$ simonii. The profile of $P$ simonii, as well as a study of the odor unit values of some identified compounds, indicated a much stronger aroma than $P$ salicina. Hexyl acetate, which produces a characteristic apple aroma, was present in $P$ simonii at levels 50 -fold higher than in the studied cultivars of $P$ salicina.
\end{abstract}

Key words: Prunus salicina, Prunus simonii, volatile compounds, plum, fruit breeding, aroma.

\section{INTRODUCTION}

The genus Prunus encompasses numerous tree crops: almond, apricot, cherry, nectarine, peach and plum. Within this genus, the plums represent one group having a wide range of genetic diversity from which traits of economic importance can be gleaned. Japanese plums ( $P$ salicina Lindl) arrived in the US during the 1880s (Weinberger 1975). Hybridizations between Japanese and native American plums at many US locations have led to numerous cultivars being adapted to a wide range of environmental conditions.

The Agricultural Research Service (ARS) has had an active fruit breeding program in Fresno, California, for the past six decades. From this location, four Japanese plum cultivars-'La Roda', 'Nubiana', 'Queen Ann' and 'RedRoy'-were named and released by the ARS in 1954. Since these initial cultivar releases, seven other Japanese plums, including 'Blackamber' and 'Friar', have been made available to stone fruit growers. These two important cultivars account for over $17 \%$ of the bearing Japanese plum acreage currently planted in California (Tippett et al 1992). Current breeding objec-

* To whom correspondence should be addressed. tives include enhancing the flavor and aroma characteristics of selections already having large fruit size, high skin color and firm flesh.

Cultivars and plum species differ in appearance, aroma and flavor. The sensory properties are very important to consumers and can be a determining factor in the development and release of new fruit cultivars. To give plant breeders the information required for these sensory attributes, it is important to known their chemical nature.

Very little has been published on plum volatiles. The first report was carried out by Forrey and Flath (1974) in $P$ salicina var 'Santa Rosa'. It was determined that acetate esters predominated the volatile compounds of plums, but there were also appreciable quantities of the higher lactones. Based on the study of Williams and Ismail (1981), linalool and ethyl butanoate are very important in the aroma of European plums $(\boldsymbol{P}$ domestica). The studies of Horvat et al (1992) with hybrids of $P$ salicina and $P$ americana demonstrated that, for most of the studied cultivars, $(E)$-2-hexenal, butyl acetate, butyl butanoate and $\gamma$-dodecalactone were the major constituents. Comparative studies of headspace volatiles between Japanese plum, apricot and interspecific hybrids between them using intact, tree- 
ripe fruit samples indicate that aromatic profiles of the studied cultivars 'Blackamber' and 'Friar' contained far fewer constituents than apricot or plum $\times$ apricot hybrids (Gómez and Ledbetter 1993).

In order to meet the objectives of developing plum cultivars with enhanced quality characteristics, it is necessary to evaluate new germplasm as it becomes available and incorporate genotypes having unique or enhanced fruit characteristics into the breeding program. Organoleptic analysis of fruit from a $P$ simonii clone during the 1992 fruit ripening season indicated a markedly more intense flavor when compared with commercial cultivars of Japanese plums. Personnel evaluating this clone reported a strong apple flavor. This clone is productive and fruit size averages $80-90 \mathrm{~g}$. The flesh is firm, orange-colored and crisp.

This study reports on the volatile constituents present in $\boldsymbol{P}$ simonii and a comparison with the profiles obtained from two $P$ salicina Lindl cultivars.

\section{EXPERIMENTAL}

Clonal accessions of 'Blackamber' and 'Friar' Japanese plums and $P$ simonii were cultivated at the ARS Horticultural Crops Research Laboratory in Fresno, California. $P$ simonii (PI 91527) was obtained from the National Clonal Germplasm Repository in Davis, California. Trees were grown in a flood-irrigated orchard, and each clonal accession was grown on 'Nemaguard' rootstock.

Fresh, tree-ripened plums were collected and immediately stored at $-18^{\circ} \mathrm{C}$ until the analysis. All analyses were performed within one month of harvest. The volatile constituents were isolated using simultaneous vacuum distillation extraction.

The fruit was cut in half and the stones were removed and discarded. The skin and pulp $(500 \mathrm{~g})$ were blended with 1.5 liters of HPLC grade water for $30 \mathrm{~s}$. 3Nonanone was used as an internal standard. The mixture was added to a 5-liter round-bottomed flask.

A modified Likens-Nickerson distillation extraction head was used (Schultz et al 1977; Takeoka et al 1988). The fruit slurry was subjected to vacuum distillation extraction $(60 \mathrm{mmHg})$ for $3 \mathrm{~h}$ with $60 \mathrm{ml}$ of hexane.

Residual water was removed by freezing the sample at $-40^{\circ} \mathrm{C}$. The hexane extract was then concentrated with a Vigreux column under reduced pressure $(200 \mathrm{mmHg}$ ) to a final volume of $0.3-0.4 \mathrm{ml}$.

The concentrated extract was injected into a HewlettPackard 5890 gas chromatograph (Hewlett-Packard, Avondale, PA). Separations were performed using a DB-5 MS column $(30 \mathrm{~m} \times 0.25 \mathrm{~mm}$, J \& W Scientific Folsom, CA). The oven temperature was programmed from 50 to $250^{\circ} \mathrm{C}\left(4^{\circ} \mathrm{C} \mathrm{min}^{-1}\right)$. Helium was used as a carrier gas and the average linear velocity was $60 \mathrm{~cm} \mathrm{~s}^{-1}$. The injector was maintained at $200^{\circ} \mathrm{C}$. The temperature of the detector (Hewlett-Packard 5971A mass selective detector) was $170^{\circ} \mathrm{C}$. The spectra were recorded at an ionization voltage of $70 \mathrm{eV}$, with a speed of 2.1 scan s $\mathrm{s}^{-1}$ over a mass range of $m z^{-1} 20-260$. Data processing was performed with a Hewlett-Packard 5895 GC ChemStation.

Sample components were identified by mass spectrum matching with a mass spectral library collection. The mass spectrum identifications were verified by comparison of the component's experimental retention index with that of authentic reference standards in most of the cases, as indicated in Table 1.

\section{RESULTS AND DISCUSSION}

Table 1 presents the volatile constituents identified and quantified in $P$ simonii and two cultivars of $P$ salicina ('Blackamber' and 'Friar'). The quantification of these compounds has to be considered approximate because the response factor of all compounds has not been calculated and all responses are considered the same as the internal standard, 3-nonanone.

In both species a total of 12 alcohols, 6 hydrocarbons, 10 aldehydes, 7 ketones, 21 esters and 4 lactones have been identified. Aldehydes and alcohols of sixcarbon atoms were identified in both species. These compounds were hexanal, 2-hexenal, hexanol, 2-hexenol and 3-hexenol. The presence of these compounds was due to the lipoxygenase activity, action initialized by the disruption of the fruit tissues when it was blended (Frankel 1982). These $C_{6}$ compounds are important to plum aroma (Ismail et al 1981) and contribute to the green note of the fruit (Guichard et al 1990).

Both $P$ salicina cultivars had very similar profiles that were quite different from $P$ simonii. In each of the volatile constituent classes, specific compounds were identified and quantified in $P$ simonii that were not present in either 'Blackamber' or 'Friar.' Of the seven identified ketones, $\alpha$-ionone appeared only in the profile of $P$ simonii. Among the alcohols, octanol, nonanol and geraniol only appeared in $P$ simonii. The number of hydrocarbons present in $P$ simonii was smaller than in $P$ salicina; however, esters were both qualitatively and quantitatively higher in $P$ simonii. Twelve of the 21 identified esters only appeared in $P$ simonii. Also, the concentration of lactones, important for the fruity aroma (Guichard et al 1990), was greater in $P$ simonii.

Esters are the main compounds responsible for the fruity aroma. Among the esters identified soley in $P$ simonii, butyl propanoate and 3-methyl-1-butyl acetate have a strong banana aroma and 2-methylpropyl butanotate and octyl acetate have a pleasant fruity aroma.

Some components were identified in both species but with great differences in their concentrations from one species to the other. These compounds were hexenal, hexanal and hexanol, the esters butyl acetate, hexyl 
TABLE 1

Concentration of the volatile compounds identified in the two plum species $\left(\mu \mathrm{g} \mathrm{kg}^{-1}\right)$

\begin{tabular}{|c|c|c|c|c|c|}
\hline Constituent & Blackamber & Friar & $P$ simonii & Identification ${ }^{a}$ & $K I^{b}$ \\
\hline \multicolumn{6}{|l|}{ Ketones } \\
\hline 2,2,6-Trimethyl-cyclohexanone $e^{c}$ & -d & - & $0 \cdot 7^{e}$ & MS & 1036 \\
\hline Isophorone & 一 & $1 \cdot 0$ & 0.8 & KI, MS & 1059 \\
\hline Acetophenone & $1 \cdot 7$ & - & - & KI, MS & 1065 \\
\hline$\alpha$-Ionone & - & - & $4 \cdot 4$ & MS & 1422 \\
\hline Dihydro- $\beta$-ionone & - & 0.4 & - & KI, MS & 1433 \\
\hline Geranylacetone & $4 \cdot 6$ & 0.6 & $5 \cdot 0$ & KI, MS & 1449 \\
\hline$\beta$-Ionone & $8 \cdot 3$ & $3 \cdot 1$ & $18 \cdot 2$ & KI, MS & 1482 \\
\hline \multicolumn{6}{|l|}{ Alcohols } \\
\hline (Z)-3-Hexen-1-ol & $6 \cdot 4$ & 12.8 & $19 \cdot 5$ & KI, MS & 849 \\
\hline (E)-2-Hexen-1-ol & $2 \cdot 5$ & $5 \cdot 0$ & - & KI, MS & 858 \\
\hline Hexanol & $32 \cdot 9$ & $12 \cdot 3$ & $357 \cdot 5$ & $\mathbf{K I}, \mathbf{M S}$ & 862 \\
\hline 4-Methylpentanol & - & - & 8.9 & MS & 874 \\
\hline 2-Ethylhexanol & $3 \cdot 7$ & 0.6 & - & MS & 1028 \\
\hline Octanol & - & - & $39 \cdot 5$ & $\mathrm{KI}, \mathrm{MS}$ & 1068 \\
\hline Linalool & $18 \cdot 0$ & $7 \cdot 6$ & $21 \cdot 1$ & $\mathrm{KI}, \mathrm{MS}$ & 1104 \\
\hline Nonanol & - & - & $8 \cdot 4$ & $\mathrm{KI}, \mathbf{M S}$ & 1178 \\
\hline$\alpha$-Terpineol & - & $1 \cdot 4$ & 3.5 & KI, MS & 1199 \\
\hline Geraniol & - & - & $3 \cdot 0$ & KI, MS & 1221 \\
\hline Nerol & $1 \cdot 0$ & - & - & KI, MS & 1251 \\
\hline Nerolidol & - & 0.7 & - & MS & 1562 \\
\hline \multicolumn{6}{|l|}{ Aldehydes } \\
\hline Hexanal & $19 \cdot 5$ & 5.9 & $93 \cdot 3$ & $\mathrm{KI}, \mathrm{MS}$ & 802 \\
\hline$(E)-2-$ Hexenal & - & 11.9 & $43 \cdot 5$ & $\mathrm{KI}, \mathrm{MS}$ & 848 \\
\hline Heptanal & $2 \cdot 5$ & 1.4 & $2 \cdot 0$ & KI, MS & 898 \\
\hline (E)-2-Heptenal & - & 0.4 & 0.8 & MS & 953 \\
\hline$(E, E)-2,4-H e p t a d i e n a l$ & $3 \cdot 3$ & - & 一 & MS & 998 \\
\hline Phenylacetaldehyde & $28 \cdot 2$ & $1 \cdot 3$ & $11 \cdot 7$ & $\mathrm{KI}, \mathrm{MS}$ & 1045 \\
\hline Nonanal & $51 \cdot 1$ & $13 \cdot 8$ & $39 \cdot 1$ & KI, MS & 1105 \\
\hline$\beta$-Cyclocitral & - & $1 \cdot 2$ & $4 \cdot 2$ & KI, MS & 1219 \\
\hline$(E, Z)-2,4-D e c a d i e n a l$ & - & -- & $4 \cdot 1$ & $\mathrm{KI}, \mathrm{MS}$ & 1295 \\
\hline$(E, E)$-2,4-Decadienal & - & - & $4 \cdot 2$ & MS & 1319 \\
\hline \multicolumn{6}{|l|}{ Esters } \\
\hline Butyl acetate & $1 \cdot 2$ & $0 \cdot 2$ & $904 \cdot 5$ & KI, MS & 813 \\
\hline 3-Methylbutyl acetate & - & -- & $30 \cdot 9$ & KI, MS & 864 \\
\hline Butyl propanoate & - & - & $2 \cdot 3$ & $\mathrm{KI}, \mathrm{MS}$ & 910 \\
\hline 3-Methyl-2-buten-1-ol-acetate & - & -- & $4 \cdot 6$ & MS & 923 \\
\hline 2-Methylpropyl butanoate & - & - & $23 \cdot 6$ & MS & 945 \\
\hline$(Z)-3$-Hexenyl acetate & $16 \cdot 1$ & $2 \cdot 8$ & $55 \cdot 3$ & KI, MS & 1005 \\
\hline Hexyl acetate & $42 \cdot 7$ & $2 \cdot 3$ & $2121 \cdot 5$ & KI, MS & 1010 \\
\hline$(E)$-2-Hexenyl acetate & $6 \cdot 4$ & 0.7 & - & $\mathrm{KI}, \mathbf{M S}$ & 1014 \\
\hline Heptyl acetate & - & - & $14 \cdot 1$ & $\mathrm{KI}, \mathrm{MS}$ & 1110 \\
\hline (Z)-3-Hexenyl butanoate & - & 0.6 & 0.4 & KI, MS & 1183 \\
\hline (E)-2-Hexenyl butanoate & - & - & $14 \cdot 7$ & $\mathrm{KI}, \mathrm{MS}$ & 1191 \\
\hline Ethyl octanoate & $4 \cdot 7$ & - & - & $\mathrm{KI}, \mathbf{M S}$ & 1196 \\
\hline Octyl acetate & - & - & $100 \cdot 9$ & $\mathrm{KI}, \mathrm{MS}$ & 1200 \\
\hline$(Z, E)$-3-Hexenyl 2-hexenoate & - & $1 \cdot 2$ & - & MS & 1228 \\
\hline Bornyl acetate & 6.0 & 0.4 & 5.9 & KI, MS & 1287 \\
\hline Pentyl hexanoate & - & - & $3 \cdot 3$ & MS & 1289 \\
\hline Nonyl acetate & - & - & $3 \cdot 4$ & $\mathrm{KI}, \mathrm{MS}$ & 1308 \\
\hline 2-Ethyl-3-hydroxyhexyl 2-methyl- & & & & & \\
\hline propanoate & - & - & 0.8 & MS & 1373 \\
\hline Geranyl acetate & - & - & $5 \cdot 2$ & KI, MS & 1377 \\
\hline (Z)-3-Hexenyl hexanoate & $13 \cdot 8$ & $9 \cdot 4$ & $9 \cdot 5$ & $\mathrm{KI}, \mathbf{M S}$ & 1376 \\
\hline Dodecyl acetate & - & - & $3 \cdot 2$ & MS & 1406 \\
\hline
\end{tabular}


TABLE 1-Continued

\begin{tabular}{|c|c|c|c|c|c|}
\hline Constituent & Blackamber & Friar & $P$ simonii & Identification ${ }^{a}$ & $K I^{b}$ \\
\hline \multicolumn{6}{|l|}{ Lactones } \\
\hline$\gamma$-Octalactone & - & - & $3 \cdot 8$ & $\mathrm{KI}, \mathrm{MS}$ & 1255 \\
\hline$\gamma$-Decalactone & $3 \cdot 1$ & - & $106 \cdot 0$ & $\mathbf{K I}, \mathbf{M S}$ & 1476 \\
\hline$\gamma$-Undecalactone & - & - & $1 \cdot 2$ & KI, MS & 1656 \\
\hline$\gamma$-Dodecalactone & $16 \cdot 1$ & $4 \cdot 8$ & $297 \cdot 8$ & $\mathrm{KI}, \mathrm{MS}$ & 1681 \\
\hline \multicolumn{6}{|l|}{ Hydrocarbons } \\
\hline 1,4-Dimethylbenzene & $2 \cdot 1$ & $0 \cdot 6$ & - & MS & 865 \\
\hline 1,2,3-Trimethylbenzene & $2 \cdot 5$ & $1 \cdot 7$ & - & $\mathrm{KI}, \mathrm{MS}$ & 966 \\
\hline Limonene & 5.9 & $1 \cdot 3$ & $3 \cdot 8$ & KI, MS & 1031 \\
\hline Naphthalene & 4.9 & 0.9 & 0.8 & KI, MS & 1186 \\
\hline 2-Ethyl-1,4-dimethylbenzene & - & $\sim$ & 1.8 & MS & 1141 \\
\hline Diethylphthalate & $4 \cdot 2$ & $1 \cdot 1$ & - & MS & 1585 \\
\hline
\end{tabular}

a Compound identified by mass spectrum (MS) and/or Kovats indices (KI).

${ }^{b}$ Experimental Kovats indices for DB-5 column.

${ }^{c}$ Mass spectra were consistent with those of reference standards.

${ }^{d}$ Not found.

e Approximate concentration since percent recovery and response factors were not determined for each compound (assuming all had a response factor of 1). The concentration values are the average of two extractions.

acetate and (Z)-3-hexenyl acetate, as well as $\gamma$ decalactone and $\gamma$-dodecalactone. These esters and lactones, together with hexanal, contribute to the plum-like aroma and the characteristic fruity flavor of $P$ simonii.

The relative contribution of various constituents to the blended plum aroma was determined by calculating the number of odor units (Uo). The odor unit was defined by Guadagni et al (1966) as the concentration of the compound divided by its odor threshold. This value gives an indication of the significance each volatile contributes to the plum aroma. Table 2 list the odor units of some plum constituents calculated from their concentrations and odor threshold (Takeoka et al 1990). The most important compounds of $\boldsymbol{P}$ salicina are $\beta$-ionone (despite its low concentration, this compound has a very low odor threshold) and nonanal, as well as hexyl acetate in 'Blackamber'. In $P$ simonii, hexyl acetate and

TABLE 2

Detection odor thresholds in water (Tc) and odor units in the $P$ salicina cultivars 'Blackamber' (Ub) and 'Friar' (Uf) and in $P$ simonii (Up) for some of the identified compounds

\begin{tabular}{|c|c|c|c|c|}
\hline Constituent & $\mathrm{Tc}\left(\mathrm{H}_{2} \mathrm{O}, \mu g\right.$ liter $\left.^{-1}\right)$ & $U b$ & $U f$ & $U p$ \\
\hline (E)-2-Hexenal & 17 & - & 0.7 & $2 \cdot 5$ \\
\hline Hexanal & 5 & 3.9 & $1 \cdot 2$ & $18 \cdot 7$ \\
\hline (Z)-3-Hexen-1-ol & 70 & $0 \cdot 1$ & $0 \cdot 2$ & 0.3 \\
\hline (E)-2-Hexen-1-ol & 400 & 0.006 & 0.01 & - \\
\hline Hexanol & 2500 & 0.01 & $0 \cdot 004$ & $0 \cdot 14$ \\
\hline Hexyl acetate & 2 & $21 \cdot 3$ & 1.6 & $1060 \cdot 7$ \\
\hline 2,2,6-Trimethyl-cyclohexanone & 2 & - & - & 0.3 \\
\hline Phenylacetaldehyde & 4 & $7 \cdot 0$ & 0.3 & $2 \cdot 9$ \\
\hline Linalool & 6 & $3 \cdot 0$ & $1 \cdot 3$ & $3 \cdot 5$ \\
\hline Nonanal & 1 & $51 \cdot 1$ & $13 \cdot 8$ & $39 \cdot 1$ \\
\hline Nonanol & 50 & - & - & $0 \cdot 2$ \\
\hline$\alpha$-Terpineol & 330 & - & 0.004 & 0.2 \\
\hline Geraniol & 40 & - & - & 0.07 \\
\hline$\gamma$-Octalactone & 7 & - & - & 0.5 \\
\hline$(E, E) 2,4$-Decadienal & 0.07 & - & - & $58 \cdot 6$ \\
\hline$\gamma$-Decalactone & 11 & 0.3 & - & 9.6 \\
\hline$\beta$-Ionone & 0.007 & $1185 \cdot 0$ & $442 \cdot 8$ & $2600 \cdot 0$ \\
\hline$\gamma$-Dodecalactone & 7 & $2 \cdot 3$ & 0.7 & $42 \cdot 5$ \\
\hline
\end{tabular}


$\beta$-ionone are the most important compounds, with the odor unit of hexyl acetate being $1060 \cdot 7$. This ester is present at a high concentration in apples (Willaert et al 1983). and is responsible for the characteristic apple-like aroma found in this species. But there are other compounds with a high odor unit value such as hexanal, described, when diluted as a plum-like aroma (Williams and Ismail 1981); nonanal, a characteristic constituent of plums skin waxes, with a fragrant woody-like aroma; $(E, E)$-2,4-decadienal and the lactones $\gamma$-decalactone and $\gamma$-dodecalactone, which are described as being responsible for the fruity, peach and coconuts background aromas of fruit (Takeoka et al 1990).

Contrasting the aromatic profiles of $P$ simonii with both 'Blackamber' and 'Friar', it appears that $P$ simonii could be a useful parental accession in a plum breeding program for its unique aromatic constituents and quantitatively important aroma compounds. Of the 60 quantified compounds identified in this study, 23 are only present in $P$ simonii. Twelve of these unique compounds are esters; taken collectively, they probably contribute to the intense fruity aroma of $\boldsymbol{P}$ simonii. Hybridizations between $P$ salicina cultivars and $P$ simonii are planned, with the objective of selecting of high levels of these important aromatic compounds in fruit of the progeny.

\section{ACKNOWLEDGEMENT}

The authors gratefully acknowledge the helpful comments of Ron G Buttery in the preparation of this manuscript.

\section{REFERENCES}

Forrey R, Flath R 1974 Volatile components of Prunus salicina, var Santa Rosa. J Agric Food Chem 22 496-498.
Frankel E 1982 Volatile lipid oxidation products. Prog Lipid Res 22 1-33.

Gómez E, Ledbetter C 1993 Transmission of biochemical flavor constituents from apricot and plum to their interspecific hybrid. Plant Breeding 111/3 236-241.

Guadagni D, Buttery R, Harris J 1966 Odour intensities of hop oil constituents. $J$ Sci Food Agric 17 142-144.

Guichard E, Schlick P, Issanchou S 1990 Composition of apricot aroma: correlations between sensory and instrumental data. J Food Sci 55 735-738.

Horvat R, Chapman G, Senter S, Roberston J, Okie W, Norton J 1992 Comparison of the volatile compounds from several commercial plum cultivars. J Sci Food Agric 60 21-23.

Ismail H, Williams A, Tucknott O 1981 The flavour components of plums: an examination of the aroma components present in the headspace above four cultivars of intact plums, Majorie's seedling, Merton Gem, NAIO and Victoria. J Sci Food Agric 32 498-502.

Schultz T, Flath R, Mon T, Eggling S, Teranishi R 1977 Isolation of volatile components from a model system. $J$ Agric Food Chem 25, 446-449.

Takeoka G, Flath R, Guntert M, Jennings W 1988 Nectarine volatiles: vacuum steam distillation versus headspace sampling. $J$ Agric Food Chem $36553-560$.

Takeoka G, Flath R, Mon T, Teranishi R, Guentert M. 1990 Volatile constituents of apricot (Prunus armeniaca L). $J$ Agric Food Chem 38 471-477.

Tippett, J, McNair T, Radenz R, Nelson D 1992 California Fruit and Nut Acreage. California Agricultural Statistics Service, Sacramento, CA, USA.

Weinberger J 1975 Plums. In: Advances in Fruit Breeding, eds Janick J \& Moore J. Purdue University Press, West Lafayette, IN, USA, pp 336-347.

Willaert G, Dirinck P, De Pooter H, Schamp N 1983 Objective measurement of aroma quality of Golden Delicious apples as a function of controlled-atmosphere storage time. $J$ Agric Food Chem 31 809-813.

Williams A, Ismail H 1981 The volatile flavor components of plums and their sensory evaluation. In: Criteria of Food Acceptance, eds Solms J \& Hall R. Forster Publ, Zurich, Switzerland, pp 333-345. 